\title{
LINGUAGEM, LÍNGUA, FALA E ALFABETIZAÇÃO: UMA REFLEXÃO SOBRE O SABER LINGUÍSTICO DO ALUNO
}

ARCENIO, Cláudia Rodrigues ${ }^{1}$

\section{RESUMO}

O presente artigo visa propor uma breve reflexão sobre alfabetização e letramento explorando alguns pontos da área da Linguística aplicada aos processos de aquisição da língua escrita. Expondo alguns conceitos inerentes a esta área do conhecimento e propondo um olhar diferenciado em alfabetização sugerindo meios de facilitar aprendizagens em lectoescrita, sobretudo em relação a alunos oriundos de classes populares. Pretende também relacionar estes conhecimentos com a perspectiva de ensino voltada às práticas propõem situações reais de uso da leitura e da escrita, além de valorizar o saber que o falante nativo possui de sua língua materna na modalidade oral como saber linguístico facilitador e indispensável para a apropriação da língua escrita.

PaLAVRAS-CHAVE: Alfabetização - Língua materna - Ensino.

\section{ABSTRACT}

This article aims to propose a brief reflection on teaching read and write and literacy by exploring some points of the area of applied linguistics language acquisition procedures written. Exposing some of the concepts inherent in this area of knowledge and proposing a differentiated look at teaching read and write suggesting means of facilitating learning, especially in relation to students from classes. Also relate this knowledge with the perspective of teaching practices focused propose real situations of use of reading and writing, as well as enhance the knowledge that the native speaker has of their mother tongue in orally as linguistic facilitator and indispensable for knowing the appropriation of the written language.

KEYWORDS: Teaching read and write - Native language - Teaching.

\footnotetext{
${ }^{1}$ Graduada em Letras (UNESA); Especialização em Alfabetização e Letramento (UGF). Professora da rede municipal de ensino em Nova Iguaçu, RJ. Email: claurodriguesmd@gmail.com
} 


\section{INTRODUÇÃO}

Realizar uma reflexão sobre alfabetização é tratar de um tema no qual grandes pensadores se detiveram expondo e propondo caminhos para auxiliar na aquisição da língua escrita. As contribuições de Emilia Ferreiro quanto ao estudo sobre as hipóteses de escrita da criança (1999) e os estudos de Magda Soares referentes ao letramento (2001), norteiam de maneira brilhante educadores que visam uma prática pedagógica fundamentada epistemologicamente em contextos reais de uso da leitura e da escrita.

Neste artigo, exporemos uma síntese de algumas concepções sobre linguagem, língua e fala que podem contribuir para o enriquecimento da prática de profissionais que se dedicam ao ensino da modalidade escrita da língua materna e que certamente auxiliarão educadores e educandos a desvendar os enigmas da tecnologia da língua escrita. Refletiremos também sobre a valorização dos conhecimentos prévios que o falante possui de sua língua materna, visando contribuir efetivamente com a prática pedagógica.

\section{A VALORIZAÇÃO DOS CONHECIMENTOS PRÉ- VIOS SOBRE A LÍNGUA MATERNA}

O Brasil é um país muito rico e plural culturalmente. Tal pluralidade nem sempre é vista como algo benéfico para a educação. Respeitar a pluralidade cultural é despir-se de preconceitos dentro e fora da sala de aula, auxiliando os educandos a construírem valores de respeito e solidariedade à sua cultura e a dos demais alunos e comunidade escolar.

Muitas vezes os próprios profissionais da educação estão revestidos de preconceitos quanto à cultura dos alunos, principalmente se tal cultura é estigmatizada socialmente como a cultura das classes economicamente mais baixas. Infelizmente a escola ao invés de buscar uma sociedade mais igualitária tem agido como uma espécie de "mecanismo de reprodução social" (SOARES. 2011 p.22) trazendo consigo os preconceitos e juízos de valor que a sociedade tenta mascarar, mas que são evidentes.

Dentre os inúmeros tipos de preconceito, um em especial pode dificultar e muito a alfabetização dos alunos: o Preconceito Linguístico (BAGNO: 2004). Segundo Marcos Bagno, o preconceito linguístico é o preconceito referente linguagem das camadas sociais de menos prestígio. Tem como instrumentos de realização a gramática normativa, os manuais que pretendem ensinar o que e como falar e os livros didáticos. (BAGNO. 2004, p.13)

A língua não é algo estático e imutável, ao contrário, é tão viva quanto seus falantes. A variação linguística e as variedades dialetais são uma realidade social e cultural. Cada aluno é oriundo de uma comunidade linguística e possui uma forma de falar e de se expressar característica de tal comunidade. Os usos e a percepção que se tem da funcionalidade da língua escrita também variam consideravelmente de acordo com a região, estado, ou nível socioeconômico do falante. Isto é, evidentemente 0 uso que determinada comunidade faz da língua escrita e a funcionalidade que esta possui pode variar de acordo com a classe social desta comunidade. Observamos que o tipo de material escrito manipulado também. É perfeitamente lógico depreender que a classe social não determina o que a pessoa pode ou não ler, mas sem dúvida esta tem influência direta em seus hábitos de leitura e escrita. Estes hábitos não estão sendo taxados como bons ou ruins, apenas estamos sinalizando as diferenças e tais diferenças podem gerar o preconceito do qual estamos tratando. Ainda sobre este tema Magda Soares comenta que o processo de alfabetização é o mais prejudicado pela discriminação: 
"Basta afirmar que o processo de alfabetização, escola, sofre, talvez mais que qualquer outra aprendizagem escolar, a marca da discriminação em favor das classes socioeconomicamente privilegiadas. A escola valoriza a língua escrita e censura a língua oral espontânea que afaste muito dela; ora, como foi dito anteriormente, a criança das classes privilegiadas, por suas condições de existência, adapta-se mais facilmente ás expectativas da escola, tanto com relação ás funções e usos da língua escrita, quanto em relação ao padrão culto de língua oral." (SOARES, 2011. p.22)

A questão do preconceito linguístico é tão séria que algumas teorias buscavam justificar o fracasso escolar na aquisição da escrita, através da variação dialetal de menos prestígio utilizado pelos alunos de classes economicamente mais baixas. Um exemplo é teoria da deficiência linguística de Basil Bernstein. Tal teoria responsabiliza o aluno pelo próprio fracasso e propõe basicamente que:

Segundo a teoria do déficit linguístico, o principal problema estaria na linguagem deficiente- no código restrito - usada pelos alunos oriundos das classes trabalhadoras. Essa linguagem se caracterizaria pelo vocabulário pobre, pela sintaxe confusa, por abundantes erros de concordância e pronúncia etc. As crianças deficitárias linguisticamente enfrentariam, assim, um grande obstáculo à aprendizagem escolar e esse déficit estaria na origem dos problemas da educação popular (SAMPAIO, 2009).

Mesmo parecendo absurda esta teoria durante muito tempo foi aceita e até mesmo norteou alguns programas de educação compensatória no Brasil, visando "compensar" a linguagem "deficiente" das crianças de classes sociais menos favore- cidas. Contudo, como poderíamos considerar deficiente uma linguagem que é utilizada diariamente, com a qual as pessoas se comunicam e interagem socialmente? Pensando desta maneira Labov, um sociolinguista norte-americano contestou a teoria propondo uma teoria menos preconceituosa e mais adequada: a teoria da diferença linguística:

Foi Labov, sociolinguista norteamericano, o criador da teoria que contestou a teoria da deficiência linguística. Estudando os dialetos utilizados por grupos étnicos específicos (negros do Harlem, "chicanos" e porto-riquenhos), Labov sustentou que a linguagem que usavam, longe de ser "restrita", "deficitária", "ilógica", era expressiva e continha uma lógica própria. A linguagem popular empregada pelas crianças dos guetos era perfeitamente estruturada como uma gramática própria e seu vocabulário era tão extenso como o de qualquer outra criança. Segundo este autor, a teoria da deficiência linguística parte da ideia preconceituosa e falsamente científica segundo a qual podem existir variedades linguísticas melhores que outras (SAMPAIO, 2009).

Estas teorias apenas corroboram o que está em discussão neste artigo. É evidente que de acordo com o meio em a criança vive os conceitos dos usos da escrita e da leitura se diferenciam. O que a criança sabe, sua cultura, sua linguagem precisam ser valorizadas em sala de aula. Os usos e as atribuições que faz da escrita devem ser considerados. O uso real que sua comunidade faz da leitura e da escrita deve ser a primeira abordagem. Adquirida as habilidades com o sistema de escrita a escola deve propor a expansão destas habilidades, para que este aluno venha a se desenvolver e apropriar-se cada vez mais e melhor da modalidade escrita de sua língua materna. 
É preciso ter em mente claramente os objetivos. Isto é, o educador e a escola precisam saber o que pretendem. Se a ideia é alfabetizar, é necessário compreender que a cultura e a língua da criança não devem ser discriminadas, mas deve ser uma fonte para facilitar e aproximar o aprendizado da realidade do aluno como ponto de partida:

Os conhecimentos linguísticos construídos por uma criança que inicia o primeiro ciclo serão tanto mais aprofundados e amplos quanto 0 permitirem as práticas sociais mediadas pela linguagem das quais tenha participado até então. É pela mediação da linguagem que a criança aprende os sentidos atribuídos pela cultura às coisas, ao mundo e às pessoas; é usando a linguagem que constrói sentidos sobre a vida, sobre si mesma, sobre a própria linguagem. Essas são as principais razões para, da perspectiva didáti$\mathrm{ca}$, tomar como ponto de partida os usos que o aluno já faz da língua ao chegar à escola, para ensinarIhe aqueles que ainda não conhece (BRASIL, 1997 p.67).

A utilidade e o valor atribuído à escrita de classes socioeconômicas diferentes também é diferente. Mostrar outros usos e ampliar os horizontes dos alunos sem dúvida também é papel da escola, mas em primeira instância o que a criança precisa aprender é como apropriar-se da escrita e da leitura e como irá utilizá-la de fato em sua comunidade. Precisam aprender também a utilizar-se de sua língua adequando-se as circunstâncias exigidas pela situação para que no futuro não continue a sofrer discriminações e estigmas sociais. Isto significa dizer que sem desvalorizar ou atribuir valores como certo/errado, ou melhor/pior o professor deverá estimular e provocar situações em que se faça mais apropriado o uso da norma culta, ou do dialeto padrão, sem com isto desvalorizar a variação dialetal utilizada pelo aluno.

Este tipo de aprendizagem faz-se necessária, pois infelizmente nossa sociedade é extremamente preconceituosa linguisticamente. Existe preconceito até mesmo em relação às variações e dialetos regionais que tanto enriquecem e embelezam a língua portuguesa falada no Brasil.

Certamente não é fácil trabalhar esta diversidade na escola, a escola sugere uniformidade, contudo o ser humano não é uniforme. E é justamente essa heterogeneidade o que pode gerar momentos de aprendizagem magníficos, aprendendo com as diferenças e proporcionando um momento de estudo relevante sobre a língua oral e escrita, seus usos e como, quando e por que utilizar-se de quais dialetos.

Refletindo mais especificamente sobre a aquisição da escrita e os conhecimentos prévios dos educandos precisamos destacar que a criança, principalmente nos grandes centros urbanos, não chega ás unidades escolares sem uma compreensão interna sobre o que é escrita:

Com o deslocamento do eixo da investigação das questões do ensino para as questões da aprendizagem, foi possível compreender que as crianças sabiam muito mais do que se poderia supor até então, que elas não entravam na escola completamente desinformadas, que possuíam um conhecimento prévio (BRASIL, 1997 p.20).

Ainda que esta compreensão não seja convencionalmente aceita por parte dos educadores como coerente, ou mesmo correta, a partir do momento que a criança entra em contato com a escrita, ela começa a elaborar conceitos inerentes a esta linguagem. Da mesma maneira, já antecipamos que nenhum conhecimento deve ser ignorado, ao contrário, todo conhecimento prévio que o educando possui de sua língua materna deve ser utiliza- 
do e aproveitado em sala de aula, valorizando e construindo, (ou ainda reconstruindo), conhecimentos e novas competências em relação à aprendizagem da leitura e da escrita.

A maneira mais eficaz para começar a desenvolver um trabalho significativo é investigar o que o aluno já sabe e assim planejar as aulas e a prática pedagógica de maneira que o educando participe de situações reais de leitura e escrita, tendo a oportunidade de redigir seus próprios textos e ler textos significativos ainda que não seja capaz de ler ou escrever convencionalmente, obtendo uma aprendizagem significativa atingindo, e porque não até ultrapassando, as competências de leitura e escrita para seu ano de escolaridade.

Ao fazer referência a textos significativos, não estamos nos referindo a textos estritamente literários ou informativos, nos referimos a estes também, porém temos a terrível tendência de relacionar o "tamanho" do texto ao seu valor significativo. Texto é uma unidade de sentido, e pode ser constituído até mesmo por uma só palavra dependendo do contexto em que está inserida. Parafraseando os PCN, até mesmo a palavra "PARE" escrita em uma placa de trânsito constitui em si uma unidade de sentido e, portanto, um texto significativo e eficaz para ser trabalhado em sala de aula.

Muitas vezes, nós educadores, mesmo sem perceber ou desejar, ainda nos posicionamos como detentores do conhecimento. Este comportamento está arraigado de tal maneira á nossa cultura que nos posicionamos desta forma involuntariamente. Contudo, isto não é desculpa para manter esta postura em sala, mas um ponto de partida primordial para a mudança efetiva de comportamento em nossa prática pedagógica. Sendo assim:

(...) Podemos continuar atuando como se a criança nada soubesse a respeito de sua própria língua? Po- demos continuar atuando de tal maneira que a obriguemos a ignorar tudo o que ela sabe sobre sua língua para ensinar-lhe, precisamente, a transcrever esta mesma língua em código gráfico? (FERREIRO, 1999 p.28)

As crianças possuem um conhecimento sobre a função da leitura e da escrita em nossa sociedade. É bem verdade que de acordo com o contexto social em que está inserida, ela terá mais ou menos informações ou até mesmo contato com a escrita e, portanto, mais ou menos oportunidades de refletir sobre seu uso. $\mathrm{O}$ que observamos, contudo, é que mesmo em grandes centros urbanos, onde há uma explosão de textos por toda parte, seja em outdoors, revistas, jornais, placas ou outros suportes de material escrito, ou seja, um ambiente onde certamente a criança já se relacionou com a escrita de alguma forma, o que aluno já sabe não é priorizado.

\section{Linguagem, Língua, fala e Alfabetiza- ÇÃo.}

Para que o aluno seja alfabetizado em língua materna, muitas vezes, como propõem alguns métodos, ele precisa esquecer os conhecimentos adquiridos como falante nativo e aprender quase que outra língua, uma língua que basicamente não existe. Segundo Cagliari:

\begin{abstract}
"A escola não parte do conhecimento que a criança tem de sua fala e da fala de seus colegas para a partir daí ensinar o que deve. A escola parte de um abecedário e de uma fala (típica de "professora primária") completamente estranha à criança" (CAGLIARI; 2009; p.25).
\end{abstract}

Certamente o método ou a prática pedagógica tem influência direta nos processos de aquisição da língua escrita pela 
criança, podendo facilitar ou dificultar esta aquisição e até o entendimento do que é a escrita e como esta se relaciona com a linguagem e língua materna do indivíduo.

\section{É importante ter consciência de} que o aluno, ao chegar à sala de aula, já faz uso da língua e a domina o suficiente para que se comunique através dela. Para os linguistas existe uma distinção muito clara entre o que é língua e sua diferenciação entre a linguagem e a fala. Vejamos algumas destas definições:

- Linguagem:

Para Ernani Terra "[...] é todo sistema de sinais convencionais que nos permite realizar atos de comunicação" (TERRA, 1997, p.12). Existem dois tipos de linguagem: verbal e não verbal. $\mathrm{Na}$ linguagem não verbal está incluída a linguagem gestual, linguagem visual e outras que não se utilizam de palavras. A linguagem verbal, no entanto, restringe-se ao uso da palavra escrita ou falada.

- Língua:

Para Roland Barthes

"[...] é a parte social da linguagem [...] Trata-se essencialmente de um contrato coletivo ao qual temos de submeter-nos em blocos se quisermos nos comunicar" (BARTHES apudTERRA, 1997, p.17).

Para Ernani Terra:

[...] é exterior ao indivíduo e, por isso, estes não podem em criá-la ou modificá-la individualmente. Ela só existe em decorrência de uma espécie de contrato coletivo que se estabeleceu entre as pessoas ao qual todos aderiram (TERRA, 1997, p.15).

Ou seja, a língua refere-se à sociedade e funciona apenas a partir de um acordo social que é inerente a comunidade falante daquela língua. É uma espécie de acordo, pois implica que todos os membros daquela comunidade atribuam um mesmo valor semântico aos vocábulos daquela língua para que haja entendimento e comunicação, que é o objetivo final da linguagem e consequentemente da língua.

- Fala:

A fala é a concretização da língua e refere-se a um ato individual do falante.

(...) A utilização que cada indivíduo faz da língua, a fala, por outro lado, possui caráter privado, ou seja, pertence exclusivamente a cada indivíduo que a utiliza. É o aspecto individual da linguagem humana (TERRA, 1997, p.16).

Para os educadores, em geral, existe uma confusão entre língua e escrita. A escrita é posterior à língua e não parte essencial desta. Basta lembrar que a maioria das interações comunicativas que fazemos acontece por meio da fala, além disso, existem as chamadas línguas ágrafas ainda vivas, pois o falante é que faz a língua manter sua função e existência. Prova disto é que línguas que não são mais faladas, mesmo com o registro escrito de sua existência são consideradas, hoje, como línguas mortas (TERRA, 1997, p.17).

Compreender que o aluno, mesmo nas séries iniciais, já domina a língua portuguesa na modalidade oral é importantíssimo para que se entendam os processos de aquisição da escrita. Enquanto falante a criança já possui noções claras do uso prático, da semântica e da gramaticalidade da língua. Isto é, quando a criança adquire a competência linguística no que se refere à fala ela internaliza os conceitos de significados, sequência lógica na construção de textos orais, organizando suas ideias de forma gramaticalmente e semanticamente 
coerentes. Elas apenas não conhecem os termos técnicos de seus conhecimentos.

Tanto Emília Ferreiro quanto o linguista Charlles Hockett abordam esta perspectiva:

Atualmente, sabemos que a criança que chega à escola, tem um notável conhecimento de sua língua materna, um saber linguístico que utiliza "sem saber" (inconscientemente) nos seus atos de comunicação cotidianos (FERREIRO, 1999, p.27).

O linguista Hockett conclui que desde cedo a criança deve ser considerada um adulto linguístico:

Pela idade de quatro a seis anos, a criança normal é um adulto linguístico [grifos do autor]. Ela domina, com pequenas exceções, se alguma, o sistema fonológico da sua língua; maneja sem esforço essencial da gramática; conhece e emprega o vocabulário básico da língua.[...] Poderá enredar-se tentando produzir discursos mais longos, como a descrição das atividades de uma manhã na escola, mas clareza em exposições extensas é um ponto em que os próprios adultos divergem muito (HOCKETT apud LUFT,1985, p.87).

O professor que compreende que a fala precede a escrita, percebe que este conhecimento completo e complexo da criança deve ser valorizado e utilizado em sala de aula como ferramenta essencial para a alfabetização. Aliás, pode ser fator determinante para que a alfabetização seja bem sucedida.

Rosa Virgínia de Mattos e Silva, em seu livro "O português são dois..." Novas Fronteiras, velhos problemas", faz uma reflexão sobre a alfabetização em língua materna coerente a este processo de alfabetização:
Qualquer indivíduo normal que entre na escola para ser alfabetizado em sua língua materna já é senhor de sua língua, na sua modalidade oral própria a sua comunidade de fala. Admitido esse princípio, qualquer trabalho de ensino da língua materna se constitui em um processo de enriquecimento do potencial linguístico do falante nativo [...] (SILVA, 2004, p.27).

O entendimento de que a escrita representa graficamente a língua, nos remete a uma perspectiva concreta do uso da escrita. Embora a escrita não faça uma transcrição perfeita da fala, pois esta é muito mais complexa em entonações e outros elementos específicos da oralidade que seriam impossíveis de transcrever, o valor da escrita está justamente em seu caráter estático e permanente em relação à fala.

Este caráter estático é atribuído ao fato de que, nas interações comunicativas que se utilizam apenas da fala, principalmente se considerarmos as interações cotidianas, as palavras originais podem se perder sendo substituídas por sinônimos, que por definição são palavras que apenas se assemelham quanto ao sentido, porém, como não existem sinônimos perfeitos em nossa língua, podem desta maneira perder um pouco de seu sentido original. Para exemplificar este fato linguístico, basta observar atos de fala em que são reproduzidas, por meio de narrações, algumas situações ou histórias. Certamente a maneira de contar o fato será modificada, pelo menos um pouco, cada vez que aquela situação ou história for recontada pelo falante, seja pelo mesmo falante ou ainda pelo interlocutor que provavelmente acrescentará a sua narrativa características próprias de sua fala que como vimos é algo individual. Ao passo que na produção escrita o leitor não assume o papel de recontar o fato, mas uma postura mais passiva de receber a mensagem e inter- 
pretá-la de acordo com sua visão de mundo, porém ainda que cada leitor tenha uma interpretação diferenciada desta mensagem, ao contrário do que ocorre na fala, esta mensagem é a mesma preservando todas as palavras originais e consequentemente o sentido original que seu emissor (escritor) propôs no momento de sua produção.

[...] a imagem gráfica das palavras nos impressiona como um objeto permanentemente sólido, mais adequado que o som para constituir a unidade da língua através dos tempos [...] (SAUSSURE, apud TERRA, 1997 p.14).

Atividades em que o professor se coloca como escriba das falas da criança a impressionam, pois ela vê sua fala concretizada na imagem gráfica da palavra.

O trabalho realizado com os nomes dos alunos, por exemplo, gera uma reflexão sobre esse caráter estático da escrita. A representação gráfica de uma palavra tão utilizada pela criança é capaz de produzir reflexões sobre o que realmente é o ato de escrever. A partir destas reflexões é possível gerar uma compreensão de como funciona, além de conferir sentido à escrita convencional viabilizando uma aprendizagem significativa dos símbolos gráficos que a tornam possível. Apresentar aos alunos uma sequência de letras arbitrariamente é uma prática comum, porém não é a ideal. A busca por uma prática pedagógica significativa, respeitando os conhecimentos prévios dos alunos, apresenta-se mais viável em termos de eficácia.

Compreender que internamente a criança já suspeita, isto é, levanta hipóteses sobre como se escreve e o que a escrita representa proporciona ao educador realizar atividades que ajudam o educando a construir novos conhecimentos e atitudes referentes à leitura e a escrita, tornando a aprendizagem da escrita convencional significativa.

Para quem já é capaz de ler e escrever entender porque devemos escrever convencionalmente (utilizando-se dos símbolos gráficos adequados) parece bem fácil, mas para quem ainda não adquiriu esta habilidade, não é tão simples. Vale lembrar que nosso sistema de escrita é totalmente arbitrário e que nem todos os sistemas de escritas utilizados pela humanidade são necessariamente alfabéticos:

Nem todos os sistemas humanos de escrita grafam os "sons" da língua (...).Há símbolos da escrita chinesa, por exemplo, que não representam sons, mas conceitos. São ideográficos. Na escrita japonesa há sinais que representam sílabas (MEC, 2008 p.31).

É necessário elaborar uma prática pedagógica de maneira que o aluno compreenda que precisamos escrever convencionalmente porque o objetivo desta escrita é a comunicação. A escrita assim como a fala é uma espécie de contrato social, e se não escrevermos de maneira que o outro compreenda, ela não tem sentido.

Durante anos temos observado uma série de equívocos em relação ao ensino de língua portuguesa nas escolas.

Primeiro como destacamos no tópico acima, desconsidera-se o domínio que o falante possui de sua língua materna e depois propõem-se exercícios e atividades que mais dificultam o entendimento do funcionamento de sua língua, que auxiliam em sua compreensão.

Observe a crítica ao ensino realizada pelo cartunista Quino: 
e-Mosaicos - Revista Multidisciplinar de Ensino, Pesquisa, Extensão e Cultura do Instituto de Aplicação Fernando Rodrigues da Silveira (CAp-UERJ)
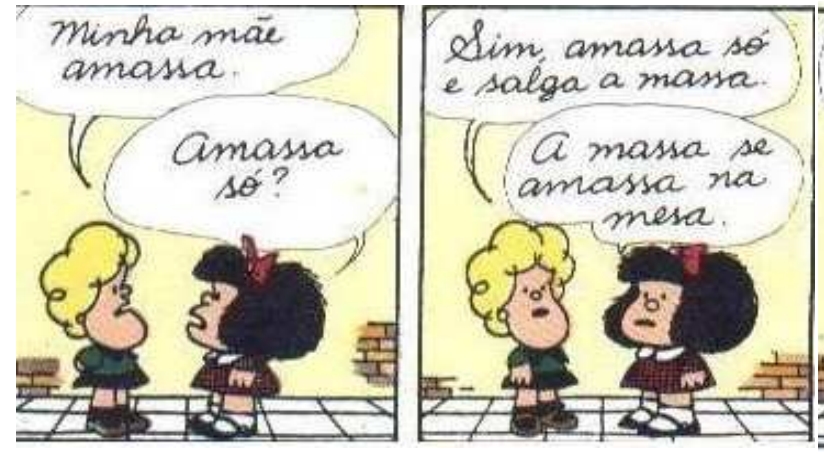
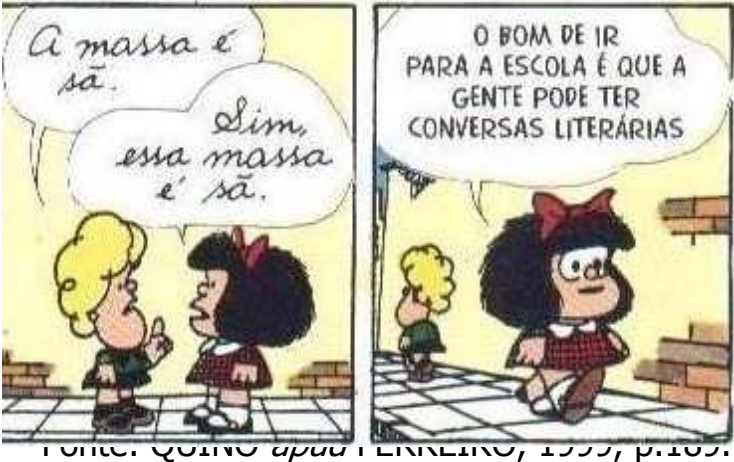

Creio que se o cartunista fosse brasileiro a conversa seria mais ou menos assim: "O boi baba." "O bebê baba." "Babi é babá do bebê.". É verdade muita coisa já mudou em relação ao ensino, entretanto não é raro, ou difícil de encontrarmos exercícios elaborados com este tipo de enunciado.

O que o educador muitas vezes não percebe é que ao iniciar os estudos sobre a língua com este tipo de enunciado estará transmitindo ao educando uma ideia distorcida da língua escrita, que obviamente não se relaciona com o conhecimento adquirido durante a aquisição da fala. Dificilmente uma criança teria este tipo de diálogo com um adulto ou outra criança, assim a criança logo dissocia a língua que está sendo ensinada na escola da língua que ela utiliza nas suas interações sociais cotidianas.

Além dessa dissociação quase que imediata, ainda atribui-se à escrita características que esta não possui, como a repetição excessiva de grafemas e fonemas e a exclusão de uma função comunicativa real. Isto é ao atribuirmos enunciados unicamente compostos de um fonema consonantal, como por exemplo: "O bebê baba.", estamos ensinando aos alunos que a escrita funciona assim e a partir desta ideia de funcionamento equivocada é que ele levantará uma considerável parte de suas hipóteses, ao inserirmos enunciados descontextualizados estamos ensinando que a escrita não possui uma finalidade definida, e como ninguém fala ou mesmo escreve desta maneira em uma situação comunicativa real, estamos sem perceber ou desejar ensinando conceitos errados sobre a natureza da escrita aos alunos.

É evidente que este processo de ensino-aprendizagem acontece de modo involuntário, mas sabemos que, no que se refere á língua, muito do que a criança aprende não está diretamente associado aos métodos utilizados na escola, ou a determinados exercícios. De fato podemos dizer que muitas vezes a criança aprende a ler e a escrever apesar do que tem sido ensinado.

Mesmo após adquirirem a escrita alfabética os problemas relacionados ao ensino da língua portuguesa persistem. Desta vez, além das questões apresentadas anteriormente, acrescentam-se outras referentes ao ensino da gramática normativa e na série de exercícios repetitivos que não levam a um conhecimento da língua nem de seu funcionamento, mas nos remetem a uma utopia sobre um uso homogêneo da língua, que desconsidera variações linguísticas geográficas, sociais, situacionais e, além disto, desconsidera o uso e a função real da língua escrita.

Para Bagno ao invés da escola dedicar-se a: 
"(...) ensinar/estudar um universo enorme e rico, que é a língua portuguesa, a escola se dedica quase exclusivamente a ensinar um pedacinho ínfimo e miserável desse universo" (BAGNO, 2002, p.50).

O autor refere-se justamente ao exclusivo ensino da gramática normativa e não o estudo da língua portuguesa. Este conceito de ensino está inserido desde as séries iniciais, cuja apropriação da língua escrita deveria ser bem mais valorizada que a simples correção dos chamados "erros de português" erroneamente denominados assim, pois muitas vezes não passam de erros gráficos, ou ortográficos, que devem ser trabalhados sim, porém não devem ser o foco do ensino, pois a língua é bem mais que sua ortografia.

As dificuldades em relação ao ensino de língua portuguesa provavelmente relacionam-se a dois questionamentos essenciais:

\section{O que ensinar? \\ Como ensinar?}

Segundo Luiz Carlos Cagliari o estudo de língua portuguesa nas escolas deve auxiliar os alunos na expansão de seus conhecimentos referentes à língua:

\begin{abstract}
"O objetivo mais geral do ensino de língua portuguesa para todos os anos da escola é mostrar como funciona a linguagem humana $e$, de modo particular, o português; quais usos que tem, e como os alunos devem fazer para estenderem ao máximo, ou abrangendo metas específicas, esses usos nas suas modalidades escrita e oral, em diferentes situações de vida" (CAGLIARI, 2009, p.24).
\end{abstract}

Sob esta perspectiva as práticas que visam um ensino contextualizado ao uso da língua tanto em sua modalidade escrita quanto oral em situações reais mostram-se eficazes para alcançar tais objetivos. Estes conceitos relacionam-se com o disposto no Parâmetros Curriculares Nacionais para ensino de Língua Portuguesa:

\begin{abstract}
A linguagem verbal, atividade discursiva que é, tem como resultado textos orais ou escritos. Textos que são produzidos para serem compreendidos. Os processos de produção e compreensão, por sua vez, se desdobram respectivamente em atividades de fala e escrita, leitura e escuta. Quando se afirma, portanto, que a finalidade do ensino de Língua Portuguesa é a expansão das possibilidades do uso da linguagem, assume-se que as capacidades a serem desenvolvidas estão relacionadas às quatro habilidades linguísticas básicas: falar, escutar, ler e escrever. (BRASIL, 1997 p.35)
\end{abstract}

\section{O ENIGMA DA ESCRITA ALFABÉTICA}

O alfabeto é algo maravilhoso, pois a partir de um número finito de letras é possível escrever um número infinito de palavras, tanto de nossa língua, quanto de outras línguas que também se utilizam do sistema alfabético de escrita.

É inegável que a aprendizagem das estruturas desta correspondência fonética é parte da aquisição da escrita. Apesar de esta afirmação parecer contrária as novas perspectivas de aprendizado da língua escrita, ela não o é. A criança, ou adulto que pretende aprender a ler e a escrever precisa conhecer o alfabeto. Não há como fugir desta realidade, pois este é essencial que se possa ler e escrever em língua portuguesa. É claro que esta não é a única, nem a principal competência linguística necessária para que a leitura ou a escrita se realize. Entretanto, faz-se indispensável, tal como as demais, para que a leitura e a escrita aconteçam. 
Reconhecer que leitura e escrita são processos distintos também é importante, para isto basta lembrar que a criança mesmo sem dominar o sistema de escrita alfabético, já é capaz de "ler" nomes de loja, rótulos, anúncios e outros textos, que através do convívio social, intuitivamente, ela infere, deduz e reconhece seu significado.

Este conhecimento precisa ser desenvolvido e trabalhado, entretanto, não é o suficiente para que aluno seja considerado alfabetizado.

Compreender que ler não é somente decifrar a escrita alfabética, também é preciso. Assim como a linguagem se refere à comunicação a leitura refere-se à compreensão e interpretação. É possível ler uma expressão corporal como o olhar, um gesto, é possível ler e interpretar um quadro famoso ou o desenho de uma criança, e através desta leitura compreender o que aquela mensagem representa e significa. Isto porque a leitura está intrinsecamente ligada ao entendimento e á compreensão da mensagem. Nesta perspectiva a leitura agrega um sentido muito mais amplo que a simples decodificação de grafemas e fonemas.

Não se trata simplesmente de extrair informação da escrita, decodificando-a letra por letra, palavra por palavra. Trata-se de uma atividade que implica, necessariamente, compreensão na qual os sentidos começam a ser constituídos antes da leitura propriamente dita. Qualquer leitor experiente que conseguir analisar sua própria leitura constatará que a decodificação é apenas um dos procedimentos que utiliza quando lê: a leitura fluente envolve uma série de outras estratégias como seleção, antecipação, inferência e verificação, sem as quais não é possível rapidez e proficiência (BRASIL, 1997 p.41).
Não estamos desconsiderando aqui que a aquisição deste conhecimento técnico da língua (a decifração), ao contrário, ele precisa ser adquirido e dominado para que a alfabetização aconteça plenamente.

Suponhamos que estamos a ler um texto qualquer, de uma receita de bolo a um texto técnico, porém, no decorrer desta leitura nos deparamos com uma palavra desconhecida. A partir do conhecimento dos vocábulos da língua materna, este leitor será capaz de depreender rapidamente dois fatos: o primeiro, se a palavra em questão pertence a sua língua realmente. Ele perceberá isto através da disposição das letras, se formam sílabas coerentes e comuns da nossa língua, se é capaz de pronunciar esta palavra sem grandes dificuldades através de seu domínio do sistema de escrita. Concluindo se aquela palavra pertence ou não a sua língua materna. A partir da constatação que esta palavra de fato pertence a sua língua se dará o segundo fato: inicia-se a tentativa de descobrir seu significado para que possa de fato lê-la e não apenas decodificá-la. Poderá fazer isto perguntando a outro falante de sua língua, relendo o texto e através do contexto deduzir seu significado, ou através da leitura tópica de um dicionário ou enciclopédia descobrir sua definição.

Entendemos, então, que é possível "ler", mesmo sem o dominar grafemas, fonemas. Entretanto esta leitura não é suficiente para considerar alguém alfabetizado no sentido de ter adquirido fluência na leitura, isto é, ser capaz de ler e compreender os diferentes tipos texto dos quais a sociedade se utiliza. É preciso também adquirir os conhecimentos técnicos referentes à tecnologia da escrita como afirma Cagliari: "A leitura é, pois, uma decifração e uma decodificação." (CAGLIARI, 2009, p.133)

O que havíamos observado anteriormente na educação era uma dissociação de ambas as competências, ensinando 
apenas as técnicas de decifração das palavras desassociadas dos textos orais e escritos que circulam na sociedade tornando este aprendizado vazio de sentido, desmotivador e inapropriado contribuindo para o fracasso na alfabetização e consequentemente para o fracasso escolar.

Observamos, em relação à escrita, que não é possível escrever, isto é, expor por meio da escrita alfabética pensamentos e opiniões de forma inteligível, sem o domínio da escrita convencional. Como bem refletem o texto de nossos PCN: (...) é fundamental que os alunos saibam que escrever, ainda que gratificante para muitos, não é fácil para ninguém. (BRASIL. MEC, 1997 p.50)

Isto porque escrever é uma construção do indivíduo, e precisa ser construída de forma a ser entendida por outrem, ou pelo próprio indivíduo em uma situação posterior a esta escrita. Neste sentido podemos dizer que 0 ato de escrever assemelha-se aos atos de fala, pois em ambas as situações, estamos produzindo discursos (textos) que precisam ser inteligíveis ao interlocutor (leitor) destinatário da mensagem. Obviamente existem diferenças infinitas entre os atos de escrever e de falar, entretanto esta é uma das semeIhanças que nos ajudam a compreender a natureza e função da escrita, pois, nas duas situações do uso da língua conservamos uma das funções primordiais de ambas vertentes da linguagem verbal: $a$ comunicação.

Para que um aluno seja considerado realmente alfabetizado ele precisa ser capaz de ler e escrever vários tipos de texto. Inclusive ser capaz de ler palavras que ele ainda não reconhece o significado, e através do contexto, auxílio de um dicionário, ou até mesmo interação social passar a conhecer seu significado e incluir esse vocábulo em seu campo lexical. Para que a escrita cumpra sua função primordial de transmitir uma mensagem em uma língua específica, é necessário que o es- criba, ou escritor possua um conhecimento, não apenas intuitivo, mas técnico de sua língua escrita.

Em língua portuguesa, este conhecimento técnico se realiza através da compreensão da correspondência fonética entre grafemas e fonemas que irão representar de maneira estática a imagem acústica da palavra, unidade de sentido presente em qualquer texto, ou discurso que se utilize da linguagem verbal.

O corpo humano não possui um aparelho específico para a fala. Utilizamosnos de outros órgãos do aparelho digestivo e respiratório para produzir os sons da fala. A estes sons denominamos fonemas, estes fonemas são representados graficamente pelas letras também chamadas de grafemas:

Grafemas são letras ou grupo de letras, entidades visíveis e isoláveis. Exemplos: a,b,c são grafemas qu, rr, ss, ch, Ih, nh também são grafemas. É preciso, então, que o aluno aprenda as regras de correspondência entre fonemas e grafemas, a partir de um trabalho sistemático em sala de aula (MEC, 2008 p.32).

Isto significa dizer que é necessário um ensino concreto e sistemático do alfabeto e do valor sonoro de seus grafemas, ou seja, faz-se necessária a aprendizagem das relações entre grafemas e fonemas para que o aprendiz seja capaz de escrever convencionalmente e para que a leitura e a compreensão dos diferentes tipos de textos seja efetuada. Entretanto este ensino não deverá estar dissociado das funções e situações reais de uso da leitura e da escrita, sobretudo quanto aos principais usos que a comunidade linguística do falante faz da língua escrita. Quando nos referimos, contudo a um ensino sistemático, de maneira alguma estamos defendendo um ensino recheado de métodos ultrapassados e descontextualizados, des- 
conectados a realidade dos alunos. Estamos falando que o ensino destes símbolos deve ser sistematizado, buscando entender a arbitrariedade da escrita e que a apropriação desta não é tão simples e intuitiva quanto a leitura de alguns textos como descrevemos no tópico acima.

A escrita é extremamente arbitrária, pois não existe um motivo pelo qual se convencionou que determinado grafema corresponderia a um som em uma língua específica e o mesmo grafema escrito exatamente da mesma forma em outra língua, ou até mesmo na mesma língua, pode ou não corresponder a um fonema idêntico. É claro que existe o alfabeto fonético que busca representar todos os fonemas conhecidos de uma mesma maneira, entretanto este alfabeto, muito mais complexo e ainda sim arbitrário, não é objeto de estudo no Ensino Fundamental. E ainda bem, pois este sistema bem mais complexo dificultaria ainda mais na aquisição da escrita.

Escrever não é algo intuitivo, requer preparo e reflexão, é um exercício mental que para quem já adquiriu este conhecimento torna-se praticamente automático, produzindo a falsa impressão de que é algo simples, quase natural.

Hoje simplesmente de olhar uma palavra escrita em uma placa ou outdoor, compreendemos instantaneamente o que está escrito, nosso cérebro adquiriu as competências de leitura a tal ponto que mesmo sem querer efetivamente ler a placa, somente de olhar para ela já efetuamos a leitura. Ainda que nunca tenhamos visto nada semelhante, ou tenha alguma relação com nosso convívio social comum. Deciframos aquela palavra sem grande esforço para relacionar grafema e fonema de forma simultânea que inferimos ou compreendemos seu sentido. Da mesma maneira acontece quando queremos escrever uma palavra, pode até surgir alguma dúvida de caráter ortográfico, porém ainda que em nossa escolha ortográfica haja algum deslize, saberemos escrever aquela palavra, pois já adquirimos a chamada escrita alfabética.

Quem está em processo de aquisição desta escrita, todavia leva um tempo maior para refletir sobre como escreverá determinada palavra. Observando os alunos é possível ver seu esforço para lembrar e escolher que grafema usará para representar graficamente os "sons" que ele produz em sua fala, ou para representar seus pensamentos.

Todavia:

A conquista da escrita alfabética não garante ao aluno a possibilidade de compreender e produzir textos em linguagem escrita. Essa aprendizagem exige um trabalho pedagógico sistemático (BRASIL, 1997 p.27).

\section{CONSIDERAÇÕES FINAIS}

Acreditamos que o ensino de língua materna no Brasil, deve objetivar que os alunos apropriem-se da língua portuguesa em sua modalidade escrita procurando expandir seus conhecimentos, ampliando suas capacidades de comunicação oral tendo em vista a adequação a diferentes situações de fala, utilizando-se de situações reais de uso da língua que levem os educandos a envolver-se em práticas sociais de leitura e escrita inserindo-os em contextos sociais diferenciados, incentivando-os a produzir e ler diferentes tipos de textos, valorizando as variedades linguísticas e pluralidades culturais existentes em nosso país.

Confiamos que estes conhecimentos referentes à Linguística e a estrutura da língua oferecem subsídios para o desenvolvimento de uma prática alfabetizadora em língua portuguesa fundamentada científica e epistemologicamente sugerindo outro olhar para a língua escrita objetivando auxiliar a apropriação da leitura e 
da escrita. É válido destacar que em nenhum momento é proposto que não se estude a gramática normativa, mas sim que não se estude somente a gramática normativa atribuindo-Ihe um valor linguístico indevido, também não é sugerido que não se estude a ortografia das palavras, mas sim que o foco do estudo seja mais amplo que nomenclaturas e grafias, que 0 foco seja o uso e as funções comunicativas da língua como forma de inclusão social capaz de promover interação entre os indivíduos possibilitando pleno exercício da cidadania.

\section{REFERÊNCIAS BIBLIOGRÁFICAS}

BAGNO, Marcos. Preconceito linguístico o que é, como se faz. São Paulo: Edições Loyola, 1999.

Língua materna: letramento, variação e ensinol Marcos Bagno, Gilles Gagné, Michael Stubbs. São Paulo: Parábola Editorial, 2002.

BARTHES, Roland. Elementos de semiologia. In: TERRA, Ernani. Linguagem, língua e fala. São Paulo: Scipione, 1997.

BRASIL. Parâmetros curriculares nacionais. 2. Língua portuguesa: Ensino de primeira à quarta série. Secretaria de Educação Fundamental, 1997.

CAGLIARI, Luiz Carlos. Alfabetizando sem o bá- bé- bi- bó- bú _ 2. ed. São Paulo: Scipione, 2009. (Coleção Pensamento e ação na sala de aula)

\section{Alfabetização e Linguística}

11.ed. São Paulo: Scipione, 2009. (Coleção Pensamento e ação na sala de aula)

FERREIRO, Emília. Psicogênese da língua escrital Emília Ferreiro, Ana Teberosky; tradução Diana Myriam Lichtenstein, Liana
Di Marco, Mário Corso. Porto Alegre: Artmed, 1999.

Reflexões sobre alfabetização_ 26.ed. São Paulo: Cortez, 2011.

Alfabetização em processo_

20.ed. São Paulo: Cortez, 2011.

FIORIN, José Luiz. (org.) Introdução à Linguística. São Paulo: Cortez, 2002.

FREIRE, Paulo. A importância do ato de ler. São Paulo: Cortez, 1982.

Pedagogia da autonomia: Saberes necessários à prática educativa. São Paulo: Paz na Terra, 1996.

GROSSI, Esther Pillar. Didática da alfabetização. v.1. Rio de Janeiro: Paz e Terra, 1990.

HOCKETT Charles. A course in Modern Linguistics. In: LUFT, Celso Pedro. Língua e Liberdade. Porto Alegre, LP\&M, 1985.

MARTINS, Maria Helena. O que é leitura. São Paulo: Brasiliense, 2003.

MEC, Pró-Letramento: Programa de Formação Continuada de Professores dos Anos/Séries Ensino Fundamental: alfabetização e linguagem. -ed. rev.e ampl. Incluindo SAEB/Prova Brasil matriz de referência. Secretaria de Educação Básica. Brasília, 2008.

MUSSALIN, Fernanda \& BENTES, Anna C. Introdução á linguística: domínios e fronteiras. São Paulo: Contexto, 2001.

SAUSSURE, Ferdinand de. Curso de linguística geral. In: TERRA, Ernani. . São Paulo: Scipione, 1997.

SILVA, Rosa Virgínia Mattos e. O português são dois: novas fronteiras, velhos 
problemas. São Paulo: Parábola Editorial, 2004.

SOARES, Magda. Letramento: um tema em três gêneros. São Paulo: Autêntica 1999.

Alfabetização e letramento.

6.ed. São Paulo: Contexto, 2011.

TARALLO, Fernando. A pesquisa sociolinguística. 7. ed. São Paulo: Ática, 2000.

TERRA, Ernani. Linguagem, língua e fala.

São Paulo: Scipione, 1997. 